\title{
Study on Default Risk based on LT model: Evidence from Chinese List Companies
}

\author{
http://dx.doi.org/10.3991/ijoe.v9iS4.2726 \\ Wang yajie, Li Hui and Yu Zhufeng \\ Harbin Institute of Technology, Harbin, China
}

\begin{abstract}
The specific credit risks can be efficiently used to defense the damage of default behavior, in which, the core problem is how to evaluate the default probability (expected default frequency, EDF) of entities. This paper measures and predicts the default probability of the listed companies in China including two kinds of sample companies such as special treatment and rating ones with the data during 2008-2009 using LT Model which argues default barrier is endogenous through the optimization of the capital structure. The result shows this approach is proper when measuring short-term default risk of listed companies.
\end{abstract}

Index Terms-default risk; default barrier; LT model; expected default Probability

\section{INTRODUCTION}

In the past 20 years, the frequent outbreak of the worldwide financial crisis has brought a profound impact on the world economy, resulting in a huge loss. Considering several major causes of the financial crisis, it is not difficult to find that the crisis caused by the default risk has the biggest destructive power on economy and needs the longest recovery period of economic capacity. The credit risk models in academic field focus mainly on two categories: one is a structural model, and the other is reduced-formed model. Structural model describes the relationship between capital structure and asset value in reality, which is a typical manifestation of the modeling of economic phenomena. Reduced-formed model stresses how various economic factors affect the value of the company assets.

Structure model is more favored by scholars for the reason of its theoretical character which linked the financial claim with economic fundamentals. The earliest proponents of the structural model is the Merton [1][2] (Morton, 1974) who believes that Changes in the value of the assets of the company subject to the random process, and the company will be in default once the asset value dropped to a critical level. The equity value is the call option of a company's assets value, and the debt value is the put option of a company's assets value. An event of default occurs when the company is insolvent. Any breach will be manifested by changes in the value of the assets of the enterprise. Its implicit assumption is: probability of default is negatively correlated with the value of the company's assets and positively correlated with the liability scale---The higher the value of the company's assets is the lower asset default probability is. At the same time the larger the size of the debt, the higher the probability of default.
The latest development of the structural model is mainly reflected in the change of the defining of default barrier [3]. It improved practice in Merton model that regard financial atrophy as fixed default barrier. Basing on the study of the default barrier, the structural model is further divided into the exogenous structural model and the endogenous structural model. The so-called "exogenous" or "endogenous" refers to that the default barrier is exogenous or endogenous [4][5].

Leland \& Toft [6][7](1994, 1996) believed that under the appropriate capital structure, the value of the company's assets takes on a diffusion random process, the value of the debt has a clear relationship with the company's risk, taxes, bankruptcy costs, risk-free interest rate and payment rate. The company can take advantage of internal managers motive of pursuit of profit maximization to control the size and structure of the company assets and liabilities, thus away from the default. So they can come to a conclusion that the company is default barrier is endogenous rather than exogenous, and this model is referred to as the LT model.

LT model make default barrier endogenous with the motive of shareholders' pursuit of profit maximization, so it is more concerned to examine the viability of listed companies. LT model reveal their credit status more essentially through estimates of the default probability of listed companies. Currently, there is no domestic literature use the LT model to measure credit risk systematically, this article will make useful attempt. Other arrangements of this paper are as follows: Firstly, comprehensive portrait mechanism of endogenous default barrier in LT model; secondly, comprehensive estimates of the credit risk of listed companies in China. Finally, make conclusions and recommendations.

\section{THE BASIC VIEWPOINT OF LT MODEL}

\section{A. Asset value of the company}

As a structural model, the LT model shows that debt and equity can be seen as the contingent claims about the value of the company assets. The value of the assets of the company is subject to the constant volatility diffusion process, namely,

$$
\frac{d V}{V}=(\mu-\delta) d t+\sigma d z
$$

Where, $V$ is the value of the assets of the company, $\mu$ is the expected rate of return of the assets of the company, $\delta$ represents the constant payout rate on assets, $\sigma$ is the 
volatility of the yield of the assets of the company, $d z$ is a standard Wiener process.

\section{B. Default barrier}

LT model argues that default barrier is endogenous. It shows that there real exists such a situation in a company that sometimes there will be a negative net asset value, namely assets less than liabilities. But the company does not go bankrupt, one of the reasons is that there is the cost of the bankruptcy liquidation, creditor losses may be greater if bankruptcy. From this perspective, both in terms of shareholders and creditors, it may be the optimal choice that the company survives to ride out the storm. The way to achieve this selection is that shareholders of the company transfer the ownership of the company's assets to creditors. Through adjust the company's capital structure, the so-called "asset substitution" is made. Default barrier is obtained endogenously through the optimization of the capital structure.

Consider the tax benefits (Because interest is pre-tax pay, equivalent to some tax relief) and bankruptcy costs, formula of the total value of the company can be gotten in this paper, the total value $(\mathrm{TV})=$ asset value + tax value of the bond - the cost of bankruptcy. Further, this paper can get that in the following: the equity value of the Company $(\mathrm{E})=$ the companies' total value (TV) - the total debt value (D):

$$
E\left(V, V_{B}, T\right)=T V\left(V, V_{B}\right)-D\left(V, V_{B}, T\right)
$$

Based on the above analysis, the following ideas can be drawn: Endogenous bankruptcy boundary $V_{B}$ is actually the lowest level continuous injection of capital to the company by equity holders. In this level, under risk neutral conditions, the expected value of equity $E$ is exactly equal to the cash value which the equity holders are willing to invest; they will give up equity below this level so that the company went bankrupt. From the mathematical sense, this means that the endogenous default boundary $V_{B}$ is determined by the following smoothness conditions:

$$
\left.\frac{\partial E\left(V, V_{B}, T\right)}{\partial V}\right|_{V=V_{B}}=0
$$

Endogenous default boundary is as follows:

$$
V_{B}=\frac{\frac{C}{r}\left(\frac{A}{r T}-B\right)-\frac{A p}{r T}-\frac{\tau C x}{r}}{1+\alpha x-(1-\alpha) B}
$$

While,

$$
\begin{aligned}
& A=2 a e^{-r T} N\left(a \sigma \frac{2}{)}\right)-2 z N(z \sigma \sqrt{T})-\frac{2}{\sigma \sqrt{T}} n(z \sigma \sqrt{T})+\frac{2 e^{-r T}}{\sigma \sqrt{T}} n(a \sigma \sqrt{T})+ \\
& B=-\left(2 z+\frac{2}{z \sigma^{2} T}\right) N(z \sigma \sqrt{T})-\frac{\sigma \sqrt{T}}{\sigma \sqrt{T}} n(z \sigma \sqrt{T})+\frac{1}{z}-a+\frac{1}{z \sigma^{2} T}
\end{aligned}
$$

$n(\cdot)$ is the probability density function of the standard normal distribution, and the corresponding, $N(\cdot)$ indicates the cumulative probability distribution of the standard normal distribution.

From the formula (4), it is can be found that endogenous default barrier is independent of the time $t$, but it depends on the period $\mathrm{T}$ of debt. In addition, it has a certain relationship with other variables, such as the corporate tax rate in the risk-free interest rate, volatility of the company's assets. Particularly evident, there is certain negative correlation between $V_{B}$ and bankruptcy costs. This suggests that for the terminable corporation debt, bankruptcy costs also affect the boundary of default, which is ignored by other structural model.

\section{Default probability}

Have got out endogenous boundary $V_{B}$ default, this paper sets the initial value of the assets of the company $V_{0}>V_{B}$, and then the probability density function $q\left(s, V, V_{B}\right)$ reaching the default barrier for the first time in the period $t$ can be further expressed as:

$q\left(s, V, V_{B}\right)=\frac{b}{\sigma \sqrt{2 \pi t^{3}}} \exp \left[-(b+\lambda t) / 2 \sigma^{2} t\right]$

Where, $b=\operatorname{Ln}\left(V_{0} / V_{B}\right), \lambda=\mu-\delta-\frac{1}{2} \sigma^{2}$. As a result, cumulative probability of default of real-world companies will be gotten within period $t$. Actually, the rate of return of the assets $\mu$ is generally calculated with the risk-free interest rate $r$. Default Probability (DP), also known as Expected Default Frequency (EDF)[8] is:

$$
\begin{aligned}
& D P(t)=N\left(\frac{-\ln \frac{V_{0}}{V_{B}}-\left(\mu-\delta-\frac{\sigma^{2}}{2}\right) t}{\sigma \sqrt{t}}\right)+ \\
& \exp \left(-\frac{\mu-\delta-\frac{\sigma^{2}}{2}}{\sigma^{2}} 2 \ln \frac{V_{0}}{V_{B}}\right) N\left(\frac{-\ln \frac{V_{0}}{V_{B}}+\left(\mu-\delta-\frac{\sigma^{2}}{2}\right) t}{\sigma \sqrt{t}}\right)_{(6)}
\end{aligned}
$$

\section{SELECTION OF SAMPLE AND CACULATING PERIOD}

In order to make more convincing measure of default risk, this research selects two types of listed companies such as special treatment (ST) companies and rating companies.

\section{A. ST companies}

To some extent, the creditors of the ST companies will be faced with credit risk, there is the possibility of occurrence of an event of default, and especially dealing with credit default exists between some of the contact. The whole of 2009, China's securities market is the 34 disted companies for special treatment (ST). In them, 25 of them are in the A-share market; among the 25 companies, 22 companies from March 13 to May 4 were in special treatment, the de facto distribution is on closer. In order to calculate available, this paper sets the uniformed approximate time of the special treatment on the April 2009, and study period in the previous year of special treatment, that is April of 2008 to March of 2009. Hence, it gets the specific calculation period as 2008 April 1 to March 31, 2009, and is further divided into four quarters, respectively, 2008.04.01-2008.06.30, 
2008.07.01-2008-09-30, 2008.10.01 2008.12.31, and 2009-01-01-2009-03-31.

This paper calculates EDF by quarter, such, after the disclosure of a listed company's latest financial report, the expected default frequency will be calculated according to the latest financial information, rather than use the annual report that may lager semi-annual report. Based on the principles of the LT model, the first quarter of 2008 is as the calculating base period and April $1^{\text {st }}$ is as $t=0$, this paper considers quarterly accumulation and calculates one by one the expected default frequency (EDF (t)) of ST companies, the cumulative period $t$ of calculation is following $\mathrm{t}=0.25, \mathrm{t}=0.5, \mathrm{t}=0.75, \mathrm{t}=1$ (year), as shown in Figure 1.

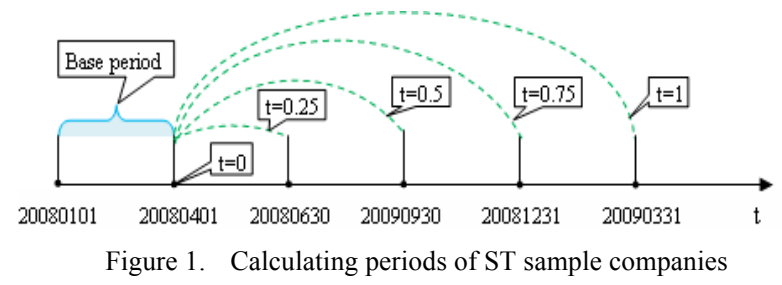

\section{B. Rating companies}

In order to make comparative analysis with the ST companies and further analyze the situation of the credit risk of listed companies in China, This paper needs to measure the credit risk of the companies with normal listed state (rating companies), which, is that the listed companies are involved in the credit rating agency but not subject to special treatment. Usually, rating companies have lower default rate.

The credit level of public disclosure of rating companies in 2009 are given by the authoritative credit rating agencies in China, such as Zhong Chengxin Co Ltd and Dagong Global Credit Rating Co. This paper selects the A-share listed companies, a total of 26, sample companies releasing from above rating agencies.

\section{SETTING PARAMETERS}

\section{A. Choice of Parameters}

According to the formula of the probability of default of the LT model, measuring the default risk of listed companies in reality needs to consider the following parameters: The value of the company's assets and the volatility of the assets; risk-free rate; corporate tax rate; rate of cost of default (bankruptcy cost rate); company's total debt, the interest on the debt; the company's debt maturity; company equity value; rate of expenditures; Equity yield volatility; expected rate of return of the assets of the company. Because it is a measure of the default risk of listed companies in China, considering the actual situation of China's enterprises, this paper makes some amendments on the determination of the parameters in the algorithm [9].

\section{$B$ VRA Method to caculate $V$ and $\sigma_{V}$}

In the above variables, the value of corporate assets and its volatility can not be directly observed [10]; their estimates are the main difficulties of the structural default risk model in the actual world, so Volatility-Restriction Approach is used in this paper. In the LT model, the company's equity is seen as a call option to the value of the assets of the company, the following relationship exists between the company return on equity volatility and asset return volatility based on Ito Lemma:

$$
\sigma_{E}=\sigma_{V} \frac{V}{E} \frac{\partial E}{\partial V}
$$

Where, $\sigma_{E}$ is the volatility of equity return, $\sigma_{V}$ the volatility of asset return, $\mathrm{V}$ is the value of the company's assets, $\mathrm{E}$ is the firm's equity, and $\frac{\partial E}{\partial V}$ is the delta value of option. Simultaneous equations of the formula (7) and formula (2), composed a binary equations:

$$
\left\{\begin{array}{l}
E\left(V, V_{B}, T\right)=T V\left(V, V_{B}\right)-D\left(V, V_{B}, T\right) \\
\sigma_{E}=\sigma_{V} \frac{V}{E} \frac{\partial E}{\partial V}
\end{array}\right.
$$

The first equation above combines observable stock price with pricing, and the second equation defines the estimated value of the tstock price volatility so as to satisfy implied in Ito Lemma in first equation, which is the origin of the name of the approach, that is so call "the limit"[11]. The equations have only two unknowns: $V$ and $\sigma_{V}$, which can be solved by numerical solution. Through MATLAB software, initial asset value $V_{0}$ and volatility of return on assets $\sigma_{V}$ can be first gotten, and then calculate the expected default frequency (EDF (t)) during period $t$.

\section{Measurement of Default Risk}

\section{A Risk measurement and result analysis of STcompanies}

$E D F$ value. The first quarter of 2008 is used as the calculating base period and April $1^{\text {st }}$ as the base day $(\mathrm{t}=0)$. After putting the parameters above in to computer program and processing the ST sample companies respectively, cumulative EDF ( $t$ ) values in different period are obtained. The descriptive statistics as are shown in the following table 1.

TABLE I.

DESCRIPTIVE STATISTICS OF EDF VALUE OF ST COMPANIES IN DIFFERENT PERIODS

\begin{tabular}{|c|c|c|c|cc|c|}
\hline & $\mathrm{t}=0.25$ & $\mathrm{t}=0.5$ & $\mathrm{t}=0.75$ & $\mathrm{t}=1$ & $\mathrm{t}=2$ & $\mathrm{t}=3$ \\
\hline Mean & 0.0003 & 0.0141 & 0.0613 & 0.1307 & 0.4152 & 0.6069 \\
\hline $\begin{array}{c}\text { Standard } \\
\text { Deviation }\end{array}$ & 0.0009 & 0.019 & 0.0675 & 0.1194 & 0.2097 & 0.2107 \\
\hline Mirimum & $1.29 \mathrm{E}-29$ & $1.01 \mathrm{E}-14$ & $9.69 \mathrm{E}-10$ & $3.03 \mathrm{E}-07$ & 0.0016 & 0.027 \\
\hline Maximum & 0.0042 & 0.0766 & 0.2907 & 0.5196 & 0.9329 & 0.9917 \\
\hline
\end{tabular}

Analysis of the measuring results. (1)Estimated EDF of special treated company is $13.04 \%(\mathrm{t}=1)$. Compared with the internationally highest default rate provided by Appraisal Company, such as Standard and Pool is $19.79 \%$ and $\mathrm{KMV}$ is $20 \%$ [12]. As a result, default rate of the sample companies in the study is relatively high, which means the credit risk of our national stock market is comparatively high. This coincides with the practical default rate after the special treatment of the sample companies. (2)it can be seen from table 1 that EDF of the 


\section{STUdy ON DEFAULT RISK BASED ON LT MODEL: EVIDENCE FROM CHINESE LIST COMPANIES}

ST companies within 2 years $(t=2)$ is $41.52 \%$. Following the rules of Basel II, In fact, 7 out of the 22 sample companies suffered the default events within 1 year after special treatment. That is to say the practical default rate is $31.82 \%$, which means LT model is suitable to ST sample companies and has a fairly good demonstration effect. (3) further analysis may be done on the relationship between the averages of EDF and $t$ within one year. Working out the average EDF of the 22 sample companies in each time period can find the relationship between average EDF of the sample companies within 1year before ST and $\mathrm{t}$ which is shown in the following Figure 2.

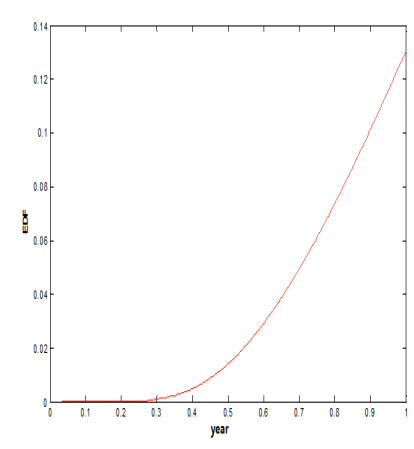

Figure2. Average EDF before the year of ST

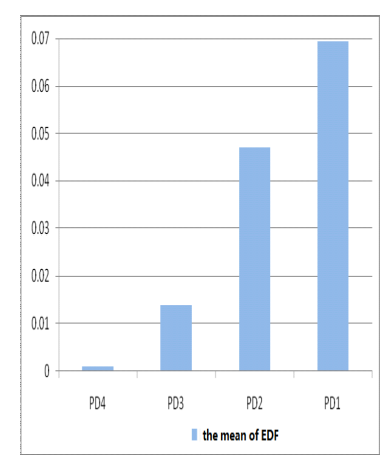

Figure 4. Average seasonal EDF before the year of ST
Here, the EDF of the sample companies one year before the special treatment is analyzed. Because $\operatorname{EDF}(\mathrm{t})$ is accumulated expected probability of default from 0 time to $t$ time and is additive, here EDF may be regarded the first quarter before ST, the second quarters before ST, the third quarter before ST and the fourth quarter before ST as PD1, PD2, PD3, PD4 (see Figure 3.) respectively, then there are as follows:

$\mathrm{PD} 1=\mathrm{EDF}(\mathrm{t}=0.25)$;

$\mathrm{PD} 2=\mathrm{EDF}(\mathrm{t}=0.5)-\mathrm{EDF}(\mathrm{t}=0.25)$;

$\mathrm{PD} 3=\mathrm{EDF}(\mathrm{t}=0.75)-\mathrm{EDF}(\mathrm{t}=0.5)$;

$\mathrm{PD} 4=\mathrm{EDF}(\mathrm{t}=1)-\mathrm{EDF}(\mathrm{t}=0.75)$.

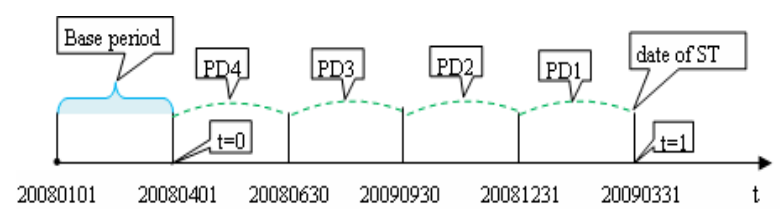

Figure 3. Average seasonal Theoretic PD(EDF) before the year of ST

The results of the estimated (theoretical) EDF in each quarter. It can be seen from the Figure 4, as the time approaches the day of special treatment, the average EDF of each company, the standard deviation, the maximum value and the minimum value increase gradually. This measurement result also proves that if a company's estimated EDF shows a rising trend three quarters, creditors should pay more attention to the credit risk of the company. That's because it means the company has a high credit risk. On the other hand, it also reveals the early warning effect of theoretical default probability worked out by the LT model.

All in all, through measurement for the default risk of the special treatment companies in the A share market, the following two intuitions got proved:(1)China's special treatment companies belongs to high default rate company.(2)with the day of special treatment approaching, the default rate shows a uprising trend.

\section{$B$ Risk measurement and result analysis of rating companies}

$E D F$ value. Taking July of $1^{\text {st }}$ as base day, the accumulative EDF are calculated. The results shows in form of descriptive statistics which can be seen in Table 2. Rating sample companies have a average EDF of $0.84 \%$ in one year $(\mathrm{t}=1)$ while that of the special treatment sample companies is $13.07 \%$, which shows that the rating companies chosen in the study has a quite low default rate.

TABLE II.

DESCRIPTIVE STATISTICS OF EDF OF RATING COMPANIES IN DIFFERENT PERIODS

\begin{tabular}{|c|c|c|cc|cc|}
\hline & $\mathrm{t}=0.25$ & $\mathrm{t}=0.5$ & $\mathrm{t}=0.75$ & $\mathrm{t}=1$ & $\mathrm{t}=2$ & $\mathrm{t}=3$ \\
\hline Mean & $3.00 \mathrm{E}-0 \mathrm{~S}$ & 0.0001 & 0.0019 & 0.0084 & 0.1025 & 0.2577 \\
\hline $\begin{array}{c}\text { Standard } \\
\text { Deviation }\end{array}$ & $6.86 \mathrm{E}-08$ & 0.0002 & 0.0031 & 0.0122 & 0.0874 & 0.1562 \\
\hline Minimum & $1.07 \mathrm{E}-92$ & $5.91 \mathrm{E}-43$ & $1.77 \mathrm{E}-26$ & $2.52 \mathrm{E}-18$ & $1.51 \mathrm{E}-06$ & 0.0042 \\
\hline maximum & $2.64 \mathrm{E}-07$ & 0.0007 & 0.0109 & 0.0419 & 0.3031 & 0.5563 \\
\hline
\end{tabular}

Results analysis of measurement. The mapping (in Figure5) shows the relationship between EDF of the rating companies and the credit rank. Generally speaking, companies with high credit rank are supposed to have relatively small EDF value. The evaluation results of the listed companies collected in this study all belong to A level, which has four specific levels: AAA,AA,AA- and $\mathrm{A}+$. Due to the limitation of the data and it is impossible to figure out the relationship between credit rank and EDF value, the mapping relation is adopted in the study to show their relationship.

The mapping relation between EDF of companies whose time limits are $0.25,0.5,0.75,1,2,3$ and the credit rank is shown in Figure 5.the horizontal axis represents the credit $\operatorname{rank}(\mathrm{AAA}$ to $\mathrm{A}+$ ) from left to right with four AAA companies, nine A companies, nine AA-companies and four $\mathrm{A}+$ companies. It is obviously seen that companies with higher credit level has fairly small EDF value and vice versa, that is to say there is a negative correlation between them. As a result, we can come to the conclusion that the EDF worked out by the LT model are effective in recognizing the credit risk of the listed companies in China.

According to the mapping relation Figure 5, we can see that compared with the AA-companies, A+ companies show comparatively low EDF value, especially in short term, which is the reason why we believe there is room for improvement in LT model. Based on the dynamic credit risk model of stock price and information disclosure market, the effectiveness of the LT model is directly influenced by the stock market. With the enhancement of our stock market, the improvement in the disclosure of the accounting information, advance in the quality of credit risk assessment, the EDF value worked out by the LT model will become more and more close to real and so will be the effectiveness of the assessment. The value of the LT model in our nation will become more and more obvious. 


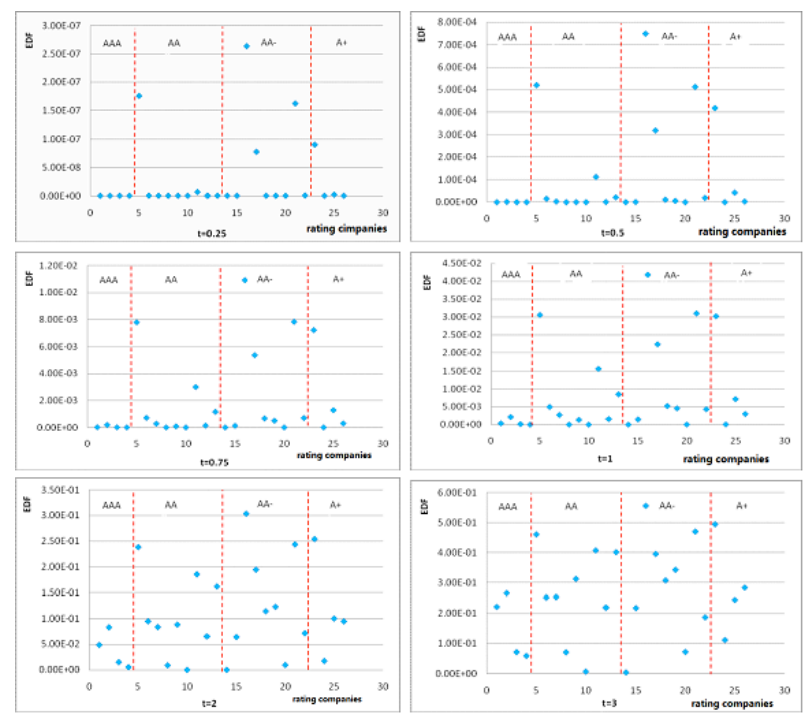

Figure 5 Mapping of EDF and credit rating of rating companies in different periods

\section{CONCLUSIONS}

This paper estimates the EDF of list ST and list rating companies and obtains the conclusions as follows: (1) listed companies with different credit levels have different EDF value, which means the higher credit one company has the lower default rate it has and the smaller the credit risk it has the better will LT model recognize the credit risk in the national listed companies. The special treatment companies among our national listed companies have quite high default rate from no matter the aspect of worked out default rate by the LT model or from the practical default rate and the international experience. (2) expected EDF value shows the similar trend as the deadline that is to say the longer the deadline is the higher default rate the listed companies have, which correspond with the current situation of the listed companies. In addition, in each period, low credit level companies have a higher default rate than the high credit level companies and the gap is prominent in the short term, which proves that LT model is more suitable for the measurement of credit risk of domestic listed companies in a short term.

\section{REFERENCES}

[1] Merton R., "On the pricing of corporate debt: The risk structure of interest rate" J. Journal of Finance, vol.29.pp449-470, May 1974.

[2] F. Black, M. Scholes, "The Pricing of Options and Corporate Liabilities", J. The Journal of Political Economy, vol.81.pp636654, May/June 1973.
[3] Black, Fischer and John C. Cox, "Valuing Corporate Securities: Some Effects of Bond Indenture Provisions", J. Journal of Finance, vol. 31 pp 351-367, May 1976. http://dx.doi.org/ 10.1111/j.1540-6261.1976.tb01891.x

[4] J. Ericsson, J. Reneby, "An Empirical Study of Structural Credit Risk Models: Using Stock and Bond Prices", J. The Journal of Fixed Income, vol. 3 pp38-49, March 2004. http://dx.doi.org/10.3905/jfi.2004.391026

[5] Longstaff, Francis A. and Eduardo S. Schwartz, "A Simple Approach to Valuing Risky Fixed and Floating Rate Debt", $J$ Journal of Finance, vol.50 pp789-819, July 1995. http://dx.doi.org/10.1111/j.1540-6261.1995.tb04037.x

[6] Leland, H.E, "Corporate Debt Value, Bond Covenants, and Optimal Capital Structure", J. The Journal of Finance, vol. 49 pp 1213-1252, September 1994.

[7] Leland, H. E., and K. B. Toft, "Optimal Capital Structure, Endogenous Bankruptcy, and the Term Structure of Credit Spreads", J. The Journal of Finance, vol. 51 pp 987-1019, July 1996. http://dx.doi.org/10.1111/j.1540-6261.1996.tb02714.x

[8] Hayne E. Leland, "Predictions of Default Probabilities in Structural models of Debt", J. Journal of Investment Management, vol. 2 pp 5-20, April 2004.

[9] Nikola A. Tarashev, "An Empirical Evaluation of Structural Credit-Risk Models", J International Journal of Central Banking, vol. 4 pp 1-53, March 2008.

[10] Anderson, Ronald and Suresh Sundaresan, "A Comparative Study of Structural Models of Corporate Bond Yields: An exploratory investigation", J. Journal of Banking \& Finance, vol. 24 pp 255269, January/February 2000. http://dx.doi.org/10.1016/S03784266(99)00059-X

[11] Ka Leung Li, Hoi Ying Wong, "Structural Models of Corporate Bond Pricing with Maximum Likelihood Estimation", J. Journal of Empirical Finance, vol. 15 pp 751-777, September 2008. http://dx.doi.org/10.1016/j.jempfin.2008.01.001

[12] Tibor Janosi, "Estimating Default Probabilities Implicit in Equity Price", J. Journal of Investment Management, vol. 1 pp 1-30, Q1 2003.

\section{AUTHORS}

Wang Yajie is with school of management, Harbin Institute of Technology, Harbin, 150001, China (email: yajiew@126.com)

Li Hui is a graduate student in school of management, Harbin Institute of Technology, Harbin, 150001, China (email: muzitian_yi@126.com)

Yu Zhufeng was a graduate student in school of management, Harbin Institute of Technology. He is with Shenyang Security Company, Shenyang, 110000, China (email: yyss-yzf@163.com)

This article is an extended and modified version of a paper presented at the International Conference on Mechanical Engineering, Automation and Material Science (MEAMS2012), held 22-23 December 2012, Wuhan, China. Received 20 April 2013. Published as resubmitted by the authors 01 May 2013. 